\title{
Effect of Drug Particle Size on Complexation, Physicochemical Properties and Dissolution of Cyclodextrin Inclusion Complexes
}

\author{
F. Al* ${ }^{*}$ J. WANG, Y. LI ${ }^{1}$ AND Y. MA ${ }^{1}$ \\ Jiangsu Key Laboratory of New Drug Research and Clinical Pharmacy, Xuzhou Medical University, Xuzhou 221004, P.R. \\ China, ${ }^{1}$ School of Pharmacy, Heilongjiang University of Chinese Medicine, Haerbin 150040, P.R. China
}

\section{Ai, et al.: Effect of Drug Particle Size on Cyclodextrin Inclusion Complexes}

\begin{abstract}
The main purpose of this study was to investigate the role of drug particle size on the complexation, physicochemical properties and dissolution of $\beta$-cyclodextrin inclusion complexes. In this work, ibuprofen in size of $3 \mu \mathrm{m}$ and $45 \mu \mathrm{m}$ (ibuprofen 3 and ibuprofen 45) were employed as the poorly water-soluble drug model. Complexation kinetics and complexation efficiency studies were conducted to investigate the complexation of ibuprofen with $\beta$-cyclodextrin in water. The solid cyclodextrins inclusion complexes were prepared with kneading method and characterized by Fourier transform-infrared spectroscopy, differential scanning calorimetry, X-ray powder difractometry, optical microscopy analyses and dissolution test. Ibuprofen with smaller particle size showed higher complexation rate with $\beta$-cyclodextrin in complexation kinetics study. By comparing the apparent stability constant, $K_{c}$ and complexation efficiency of complexes, it also indicated that smaller drug particles are more efficient to interact with $\beta$-cyclodextrin than larger particles. The phase solubility diagram could be classified as Bs type, which denotes complexes with limited solubility. The Fourier transform-infrared spectroscopy, differential scanning calorimetry, $X$-ray powder difractometry and optical microscopy analyses confirmed the formation of $\beta$-cyclodextrin inclusion complexes with ibuprofen 3 or ibuprofen 45. In the dissolution study, the inclusion complexes presented faster dissolution rate on contrast with the physical mixtures and pure drugs. What is more, the inclusion complexes prepared with ibuprofen in small particle size showed improving dissolution rate than in large particle size.
\end{abstract}

Key words: $\beta$-cyclodextrin, ibuprofen, particle size, inclusion complex, complexation efficiency

An increasing number of potential drug candidates have emerged with the development of combinational chemistry, genomics and high throughput screening techniques $^{[1]}$. Among these new drug chemicals, it is estimated more than $40 \%$ of them are poorly water soluble ${ }^{[2,3]}$. Water solubility is an essential drug characteristic for drug development. Insoluble drugs often have a variety of limitations, including low dissolution rate, poor absorption and low bioavailability $^{[4]}$. For oral administration, poorly water soluble drugs have slow drug dissolution rate and poor absorption in the gastrointestinal tract $\mathrm{t}^{[2]}$, whereas on intravenous administration, side effects and toxic effects might come as a result of the precipitation and aggregation of poorly water soluble drugs ${ }^{[5]}$. Therefore, attempts to improve solubilization and enhance bioavailability of poorly water-soluble drugs are very important and remain one of the most challenging aspects in pharmaceutical field.

Over the years, great efforts have been made to enhance

*Address for correspondence E-mail: afew2012@163.com

January-February 2017 the solubility of the poorly water soluble drugs, different formulation approaches and techniques have been developed to improve their oral absorption by increasing the solubility or dissolution rate ${ }^{[6]}$. In these approaches and techniques, formulating cyclodextrin inclusion complex is widely used to improve the solubility of hydrophobic drugs ${ }^{[7]}$. Cyclodextrins are cyclic oligosaccharides made up of 6-8 dextrose units ( $\alpha-, \beta-, \gamma$-cyclodextrins, respectively) joined through 1-4 bonds with a relatively lipophilic inner cavity and a hydrophilic outer surface, which can incorporate polar molecules or parts of molecules inside their hydrophobic cavities. $\beta$-cyclodextrin ( $\beta$-CD, fig. 1a) and its derivatives are the most widely used because

This is an open access article distributed under the terms of the Creative Commons Attribution-NonCommercial-ShareAlike 3.0 License, which allows others to remix, tweak, and build upon the work non-commercially, as long as the author is credited and the new creations are licensed under the identical terms

Accepted 25 January 2017

Revised 05 December 2016

Received 05 July 2016

Indian J Pharm Sci 2017;79(1): 131-138 
they are readily available and of low-toxicity and moreover, they provide pharmaceutically useful complexation characteristics with a wide range of drugg $^{[6]}$. There are currently $\sim 30$ different cyclodextrincontaining pharmaceutical products in the market in $\sim 14$ different types of formulations worldwide ${ }^{[8,9]}$. It is essential to use as small amount of cyclodextrins as possible in pharmaceutical formulations. Using cyclodextrins in large amounts will lead to problems including toxicological consideration, production cost, formulation bulk, drug bioavailability and isotonicity ${ }^{[10]}$. The formulation bulk is a major barrier to large scale use of cyclodextrins. Therefore, increasing the drug loading ability of cyclodextrins by enhancing their complexation efficiency may expand the use of cyclodextrins. And both those drug candidates and marketed drugs will benefit from this technology ${ }^{[11]}$. Investigators have tried various methods to increase the drug loading ability of cyclodextrin, including drug ionization $^{[12]}$, processing approaches ${ }^{[13]}$, addition of polymers $^{[14,15]}$, cosolvents ${ }^{[16]}$.

Particle size reduction approach is an effective method to increase dissolution rate of hydrophobic drugs as preparing cyclodextrins inclusion complex. It is well recognized that particle size reduction can increase the specific surface area and dissolution rate will be improved in proportion with the more effective surface area of the drug ${ }^{[17]}$. Therefore, particle size reduction may increase the surface area of drug accessible to the cyclodextrins. The complexation rate and complexation efficiency of drug/cyclodextrin may benefit from particle size reduction. Furthermore, dissolution rate of inclusion complex prepared with small particle size could be increased due to its residual free drug.

The aim of the present work was to investigate whether the drug particle size influence the complexation, physicochemical properties and dissolution behaviours of drug/cyclodextrins (fig. 1). Ibuprofen (IBU, fig. $1 b)$ is widely used as analgesic and antiinflammatory drug. It has low water solubility and high permeability across biological membranes. IBU is classified as a class II drug in the Biopharmaceutics Classification System (BCS), whose bioavailability is strongly affected by its dissolution rate. In most cases, the administration of conventional form of IBU has no ideal biopharmaceutical and pharmacological effect due to its low dissolution rate ${ }^{[18,19]}$. In this work, micronized IBU in size of $3 \mu \mathrm{m}$ and $45 \mu \mathrm{m}$ were used to prepare inclusion complexes with $\beta-\mathrm{CD}$, and then their complexation efficiency, physicochemical properties and dissolution rate were studied.

\section{MATERIALS AND METHODS}

IBU ( $>99 \%$ purity) was purchased from Hubei Granules-Biocause Pharmaceutical Co., Ltd. (Hubei, China). Two different particle size of IBU were used in the reported experiments: IBU 3 and IBU 45, having volume median particle size $\left(\mathrm{d}_{50}\right)$ of $3 \mu \mathrm{m}$ and $45 \mu \mathrm{m}$, respectively. $\beta-\mathrm{CD}$ (Cavamax ${ }^{\circledR}$ W7 Pharma) was kindly gifted from Ashland Inc., USA. All other chemicals

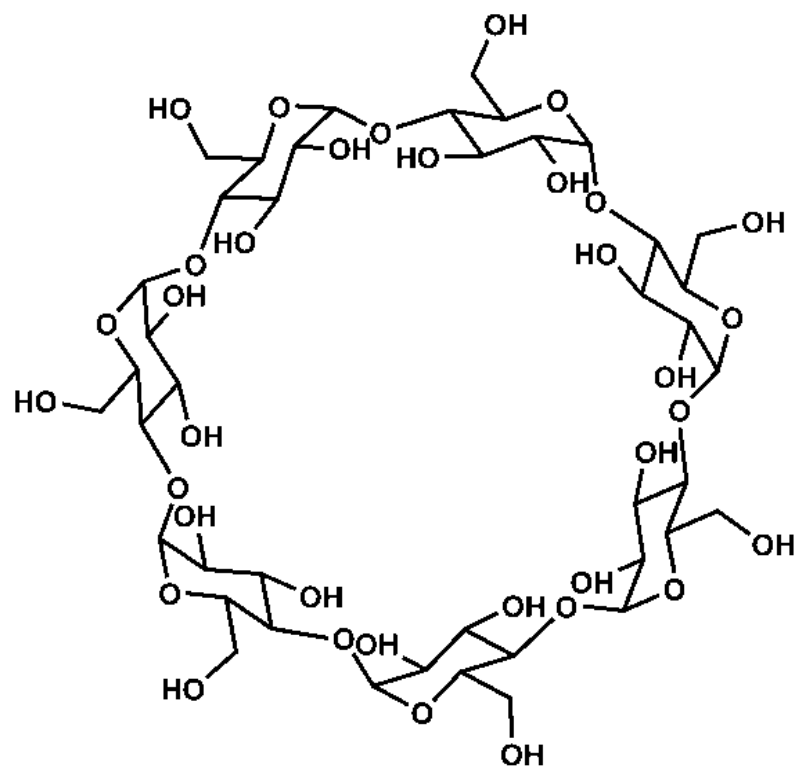

$\mathbf{a}$

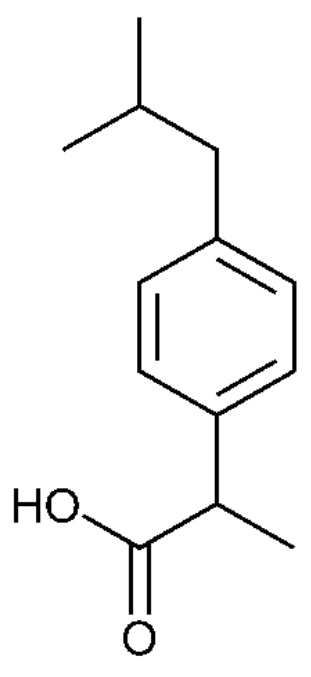

b

Fig. 1: Chemical structures

a. $\beta$-cyclodextrin; b. IBU 
used were analytical grade and double-distilled water was used throughout the study.

\section{Determination of IBU:}

An assay method for IBU was developed and validated based on UV spectroscopy (Shimadzu-UV 2450, Japan) using a wavelength of $265 \mathrm{~nm}$ and $0.1 \mathrm{~mol} / 1 \mathrm{NaOH}$ as solvent. The linearity range was found to be 0.1-0.4 $\mathrm{mg} / \mathrm{ml}\left(\mathrm{R}^{2}=0.9996\right)$. This method was established to be accurate, precise and selective for the analysis of ibuprofen pharmaceutical formulation.

\section{Complexation efficiency and complexation kinetics study:}

Complexation efficiency of $\beta-C D$ with IBU in two different particle sizes was evaluated by comparing their apparent stability constants $\left(\mathrm{K}_{\mathrm{c}}\right)$ and the complexation efficiency (CE) values in phase solubility study. Phase solubility experiment was carried out in a water bath shaker according to the method described by Higuchi and Connors ${ }^{[20]}$. Excess amount of IBU 3 or IBU 45 was added to $10 \mathrm{ml}$ of aqueous solution with increasing concentration of $\beta-\mathrm{CD}(0.88-14.10 \mathrm{mmol} / \mathrm{l})$ and shaken at $25 \pm 0.1^{\circ}$ for $2 \mathrm{~h}$ to reach the solubility equilibrium. The suspensions were filtered by 0.45 $\mu \mathrm{m}$ PES filter, and the concentration of ibuprofen was determined by a UV spectrophotometer. The $\mathrm{K}_{\mathrm{c}}$ and $\mathrm{CE}$ of the 1:1 (guest:host) complex were calculated from the slope of the phase solubility diagrams using the following Eqns. ${ }^{[20,21]} \mathrm{K}_{\mathrm{c}}=$ slope/ $\mathrm{S}_{0}$ (1-slope); $\mathrm{CE}=$ slope/(1-slope). The slope is obtained from the initial straight-line portion of the plot of ibuprofen concentration against $\beta-C D$ concentration, where $S_{0}$ is the equilibrium solubility of IBU in water without $\beta-C D$.

Complexation kinetics study was carried out at $25 \pm 0.1^{\circ}$. Accurately weighted IBU 3 or IBU 45 in molar ratio of $1: 1$ with $\beta$-CD were added to $30 \mathrm{ml}$ of water solution of $\beta$-CD (1.76 mmol/1, $5.28 \mathrm{mmol} / \mathrm{l}, 8.81 \mathrm{mmol} / \mathrm{l}$, respectively), and then shaken in a water bath shaker at $100 \mathrm{rpm}$. At 5, 10, 15, 25, 40, 60, 90, 120, $180 \mathrm{~min}$, $2 \mathrm{ml}$ of the mixture was taken out and filtered by 0.45 $\mu \mathrm{m}$ PES filter. After appropriate dilution, each filtrate was analysed by a UV spectrophotometer at $265 \mathrm{~nm}$ as described above against blank control of $\beta-C D$.

\section{Preparation of inclusion complexes and physical mixtures (PMs):}

Solid inclusion complexes of IBU and $\beta-C D$ were prepared in a 1:1 molar ratio by kneading method with IBU 3 and IBU 45. The accurately weighed IBU and
$\beta$-CD with small amount of water were kneaded in a mortar for $30 \mathrm{~min}$. During this process, appropriate amount of water was added to the mixture to keep it pasty. The resulting paste was dried at $45^{\circ}$ for $8 \mathrm{~h}$. The dried complexes were pulverized into fine powder and sieved through 100 mesh sieve. It was then stored in a desiccator for further determination.

PMs were prepared by homogeneous blending of previously sieved and weighted ibuprofen (IBU 3 and IBU 45 , respectively) and $\beta-C D$ in a mortar in 1:1 molar ratio. Then the PMs were sieved through 100 mesh sieve and stored in a desiccator for further determination.

\section{Characterization of inclusion complexes and PMs:}

Fourier transform infrared spectra (FTIR) of IBU, $\beta-C D$ and their binary products were obtained with Shimadzu FTIR-8400s spectrophotometer. Dried samples with potassium bromide were previously ground and mixed thoroughly, compressed into transparent disk and analysed on spectrophotometer. The scan region was $4,000-400 \mathrm{~cm}^{-1}$ with resolution of $2 \mathrm{~cm}^{-1}$. The inclusion complexes and PMs contained the same amount of IBU, the ratio of IBU and potassium bromide was constant in the experiment in order to evaluate the IR spectra.

Differential scanning (DSC) calorimetry thermal analysis of pure IBU, $\beta-\mathrm{CD}$ and their binary products were carried out using a NETZSCH DSC 200 F3 instrument. The samples of approximately $4 \mathrm{mg}$ were sealed in aluminium pans and heated over a temperature range of $30-150^{\circ}$ at a heating rate of $10^{\circ} \%$ min under nitrogen gas purge at a flow rate of $60 \mathrm{ml} /$ min. An empty sealed aluminium pan was used as the reference.

X-ray powder diffractometry (XRPD) spectra were obtained with a BRUKER D8 Advance diffractometer system with monochromatic $\mathrm{Cu} / \mathrm{Ka}_{1}$ radiation. The voltage and current were at $40 \mathrm{kV}$ and $30 \mathrm{~mA}$. The diffraction patterns were recorded with $2 \theta$ range of $2-30^{\circ}$ with a step size of $0.025^{\circ}$.

The surface morphology of ibuprofen, $\beta-\mathrm{CD}$ and their binary systems was analysed by an optical microscope (OLYMPUS-CX21FS1). Samples were mounted on a glass slide, viewed under normal light and pictures were taken with a GY-5000 camera (Nanjing Guangyou Optical and Electrical Instrument Co. Ltd).

The dissolution rate studies of IBU, IBU/ $\beta-C D$ inclusion complexes and PMs were carried out in a dissolution apparatus (ZRS-8, Radio Factory of Tianjin 
University, China) using the paddle method at $37 \pm 0.5^{\circ}$, $50 \mathrm{rpm}$. The release media was a solution of sodium dodecyl sulphate $(0.1 \%$, w/v) $900 \mathrm{ml}$. Approximate $100 \mathrm{mg}$ of ibuprofen or its equivalent amount of IBU/ $\beta$ $\mathrm{CD}$ inclusion complexes and PMs were dispersed into dissolution vessels. The samples $(5 \mathrm{ml})$ were taken out at $5,10,15,30,45,60,90,120 \mathrm{~min}$, filtered using 0.45 $\mu \mathrm{m}$ PES filter and analysed by UV spectrophotometer after appropriate dilution as described earlier. Meanwhile, $5 \mathrm{ml}$ of fresh release media was added in order to maintain the volume of dissolution medium.

\section{RESULTS AND DISCUSSION}

The phase solubility diagrams were obtained by plotting the apparent concentration of IBU against the concentration of $\beta-C D$ and shown in fig. 2. The diagrams showed that the solubility of IBU linearly increased with $\beta-\mathrm{CD}$ concentration from 0.88 to $5.28 \mathrm{mmol} / \mathrm{l}$. However, the solubility of IBU slightly decreased with an increase of $\beta$-CD concentration from 5.28 to $14.10 \mathrm{mmol} / \mathrm{l}$. This diagram could be classified as Bs type as described by Higuchi and Connors ${ }^{[19]}$. This result was consistent with the phase solubility studies of ibuprofen with $\beta$-CD reported by Ghorab et al. and Salústio et al. ${ }^{[22,23]}$ The Bs type denoted complexes with limited solubility ${ }^{[24]}$. The apparent stability constants $\left(\mathrm{K}_{\mathrm{c}}=2209.26,1974.08 \mathrm{M}^{-1}\right.$ for IBU 3 and IBU 45, respectively) for the complexes were calculated based on the linear portion of the diagram. Meanwhile the CE was calculated to be 1.07 and 0.98 for IBU 3 and IBU 45, respectively. These differences suggested that particle size reduction could enhance the interactions between drug and $\beta-\mathrm{CD}$. The maximum of apparent solubility of IBU was obtained in the presence of $\sim 5.28$ $\mathrm{mmol} / 1 \beta-\mathrm{CD}$, and there was 6 -fold enhancement in the solubility in comparison with the ibuprofen alone in water (fig. 2).

The complexation kinetics diagrams were obtained by plotting the apparent concentration of the drug against complexation time as shown in fig. 3. The plots of three concentrations of $\beta-C D$ showed the apparent concentration of IBU increased with complexation time from 5 to $90 \mathrm{~min}$. After $90 \mathrm{~min}$, the apparent concentration of IBU was stable, which meant the complexation equilibrium was reached. There were 2 possible explanations for the differences in solubility of IBU 3 and IBU 45: firstly, the IBU 3 with smaller particle size could promptly dissolved in water due to its larger effective surface area; secondly, since the solubility of ibuprofen is limited, it reasonable assumed that IBU 3 could form inclusion complex with $\beta-C D$ more rapidly. In conclusion, the particle size reduction presented a positive effect on the formation speed of the inclusion complex for IBU 3 showing high apparent concentration with $\beta-\mathrm{CD}$ in comparison with IBU 45 at a fixed time. Furthermore, the highest apparent concentration of IBU was not increased with $\beta-C D$ concentration, which might attribute to the limited solubility of the inclusion complex. This result was consistent with the following phase solubility study (fig. 3).

IR spectra of IBU, $\beta-C D$, and their binary systems are presented in fig. 4 . The spectrum of IBU showed the characteristic peaks of the drug. A stretching band at $1720 \mathrm{~cm}^{-1}$ can be attributed to the carbonyl group, the peaks at $2955 \mathrm{~cm}^{-1}$ confirm the presence of $\mathrm{O}-\mathrm{H}$ bending, the presence of peaks at $1420,1231 \mathrm{~cm}^{-1}$ confirm C-C stretch and C-H stretching for IBU (fig. 4a and $b)^{[23,25]}$. The spectra of IBU in two particle size show no obvious difference, which indicates the particle size reduction do not influence the drug IR spectroscopy. $\beta$-CD spectrum (fig. 4c) shows characteristic absorption bands at 1639, 1157, $1028 \mathrm{~cm}^{-1}$ and a broad absorption band around $3383 \mathrm{~cm}^{-1}$ due to $\mathrm{O}-\mathrm{H}$ stretching. The physical mixture shows spectrum (fig. $4 \mathrm{~d}$ and e) corresponding to a superposition of their parent components (fig. $4 \mathrm{a}, \mathrm{b}$ and $\mathrm{c}$ ) with no significant shift in the major peaks $\left(1720,1420,1231 \mathrm{~cm}^{-1}\right.$ bands arising from IBU, and 3383, 1157, $1028 \mathrm{~cm}^{-1}$ bands attributing to $\beta-C D)$, indicating that no interaction had occurred in the physical mixture between the free drug and $\beta-C D$. However, in the inclusion complexes, the ' $\mathrm{C}=\mathrm{O}$ ' stretching band at $1720 \mathrm{~cm}^{-1}$ arising from

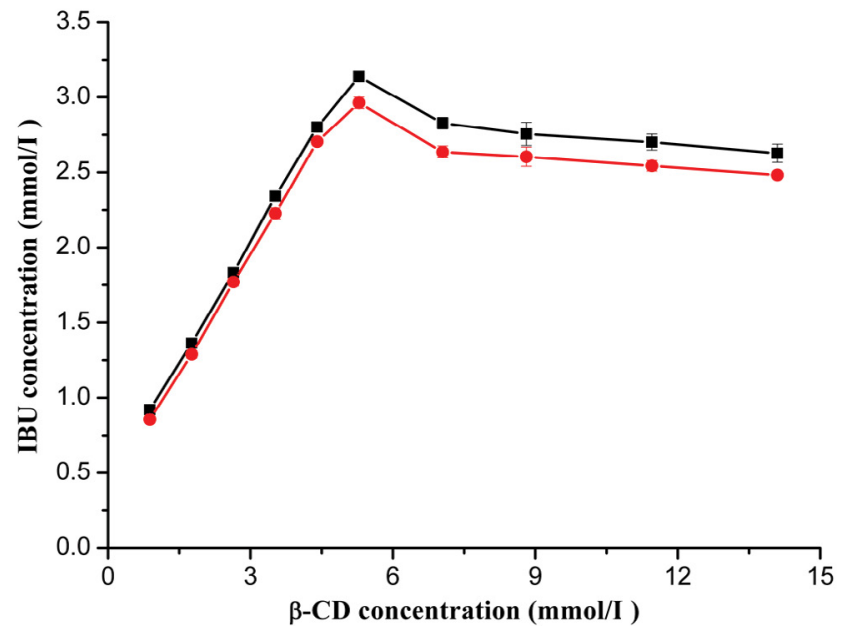

Fig. 2: Phase solubility diagram of IBU/ $\beta$-cyclodextrin inclusion complex

The values are in mean \pm SD, $n=3$, - - - IBU 3, - •- IBU 45 


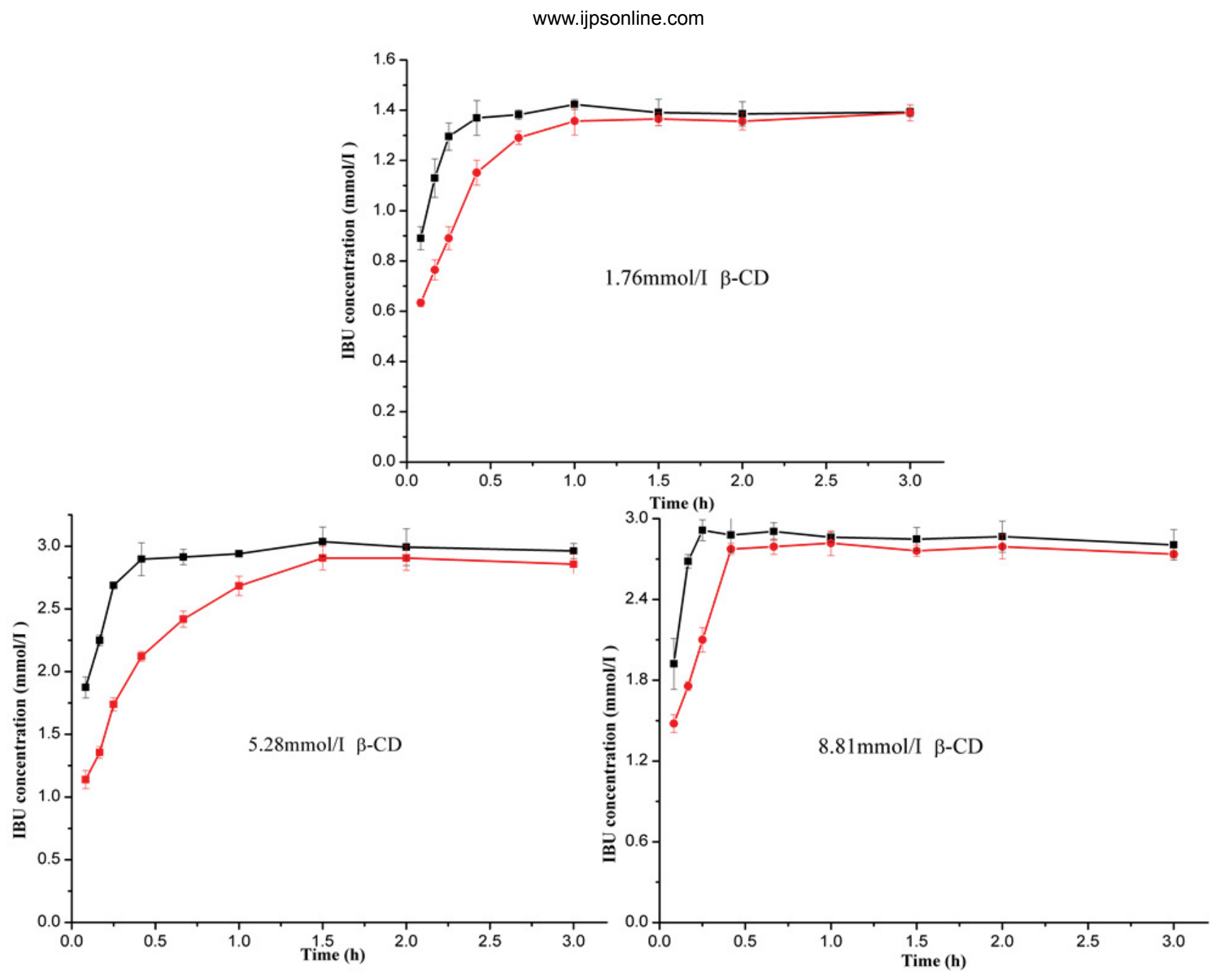

Fig. 3: The complexation kinetics diagrams of IBU and $\beta-C D$ The values are in mean $\pm S D, n=3$, - - - IBU 3 , - $\bullet$ - IBU 45

ibuprofen shifts to 1732 or 1718 and 1732 or $1717 \mathrm{~cm}^{-1}$ for IBU 3 and IBU 45 inclusion products, moreover, the intensity of the ' $\mathrm{C}=\mathrm{O}$ ' stretching band is much weaker than corresponding PMs. In addition, a shift to lower wave number $\left(3356 \mathrm{~cm}^{-1}\right)$ attribute to $\mathrm{O}-\mathrm{H}$ stretching is observed in the inclusion complexes. These differences in the IR spectra indicate the interactions of IBU and $\beta-\mathrm{CD}$ and the formation of inclusion complexes (fig. $4)^{[22,26]}$.

Thermal DSC analysis has been widely used to confirm formation of inclusion complex between drug and $\mathrm{CD}$ by comparing the thermal behaviours of the individual components and their binary systems ${ }^{[13,27]}$. DSC thermograms of IBU, $\beta-C D$, and their binary systems are shown in fig. 5. IBU presents a single sharp endothermic peak at $76.9^{\circ}$ and $78.5^{\circ}$ for IBU 3 (fig. 5a) and IBU 45 (fig. 5e), which corresponds to its melting point. The small difference in melting point of IBU 3 and IBU 45 may attribute to the reduction of particle size ${ }^{[28]}$. After melting, IBU shows suitable stability in the investigated temperature interval. The DSC curve of IBU exhibited a typical behaviour of anhydrous crystalline drug. $\beta$-CD showed a broad endothermal peak at about $90^{\circ}$, which could be attributed to the release of crystal water. In the thermal curve of the PMs, both the characteristic endothermic melting peak of IBU and endothermic water loss peak of $\beta-C D$ are observed. However, the endothermic peak of IBU is absent in the DSC curve of the inclusion complexes, which indicates the formation of IBU/ $\beta-C D$ inclusion complex. Furthermore, the PMs and inclusion complex prepared with IBU 3 and IBU 45 present no obvious difference in the thermal curve (fig. 5).

XRPD is an effective method for the detection of solid inclusion complexes in powder or microcrystalline states $^{[29,30]}$. Fig. 6 shows the diffraction patterns IBU, $\beta-C D$, and their binary systems. IBU 3 presents diffraction peaks at $2 \theta$ of $6.1,12.2,13.9,16.6,17.6$, 19.5, 20.1 and $22.3^{\circ}$, while IBU 45 diffraction peaks appear at $2 \theta$ of $6.2,12.3,16.8,18.8,19.1$ and $22.4^{\circ}$. 


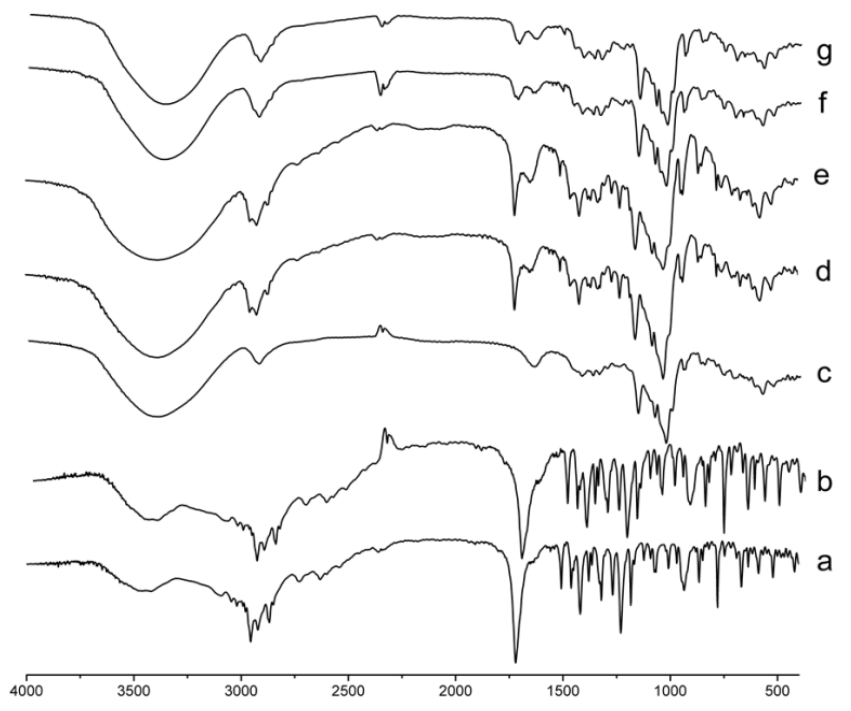

Fig. 4: IR spectra

a. IBU 3, b. IBU 45, c. $\beta$-cyclodextrin, d. physical mixture with IBU 3, e. physical mixture with IBU 45, f. inclusion complex with IBU 3 and g. inclusion complex with IBU 45

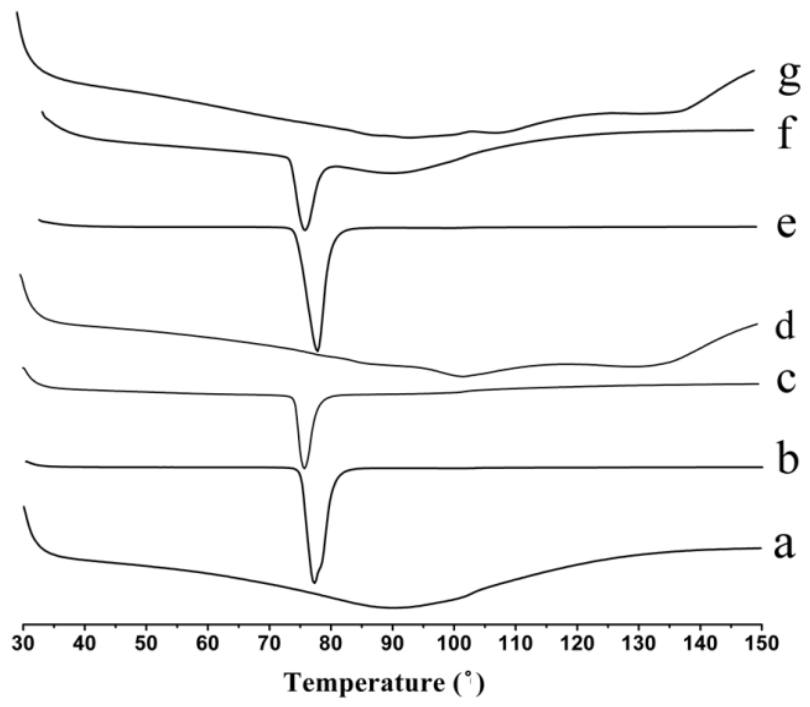

Fig. 5: DSC thermograms

a. IBU 3, b. IBU 45, c. $\beta$-cyclodextrin, d. physical mixture with IBU 3, e. physical mixture with IBU 45, f. inclusion complex with IBU 3 and g. inclusion complex with IBU 45

These sharp peaks observed in both IBU 3 and IBU 45 diffraction patterns suggest a crystalline nature of ibuprofen. However, IBU 3 presents more diffraction peaks than IBU 45. For example, the IBU 3 peaks at $2 \theta$ of 13.9 and $20.1^{\circ}$ are not existed in IBU 45. The difference in their diffraction peaks for IBU 3 and IBU 45 is attributed to the reduction in particle size ${ }^{[29]} \beta-\mathrm{CD}$ shows peaks at $2 \theta$ of $4.6,10.7,12.9,13.5$ and $18.2^{\circ}$. The strong diffraction peaks of $\beta-C D$ indicate its crystalline character. The XRPD patterns of the physical mixture are almost a superposition of the patterns contributed by $\beta-C D$ and IBU. The characteristic diffraction peaks of $\beta-\mathrm{CD}, \mathrm{IBU} 3$, and IBU 45 are detected in corresponding physical mixture, but IBU presents lower intensity due to its smaller quantity. The diffraction patterns of PMs prepared with IBU 3 or IBU 45 reveal the presence of free crystalline drug and $\beta-C D$. In contrast, the diffraction pattern of IBU/ $\beta-C D$ inclusion complex shows almost complete disappearance of the principal diffraction peaks coming from IBU and $\beta-C D$, and some new broad diffraction peaks with low intensity at $2 \theta$ of $\sim 6.5,11.7,17.5,19.0^{\circ}$ are detected. The IBU $45 / \beta-C D$ inclusion complex shows a sharp peak at $2 \theta$ of $6.1^{\circ}$ coming from IBU, which reveals the presence of free crystalline drug. Changes in these diffraction peaks may suggest the formation of $I B U / \beta-C D$ complexes (fig. 6).

Optical microscopy analysis is a fast and relatively inexpensive technique to confirm the formation of drug/CD complex by comparing the shape and particle size of $\beta-C D$, IBU and their binary systems ${ }^{[23,31]}$. The photomicrographs of samples are shown in fig. 7. The particles of $\beta-\mathrm{CD}$ are observed as rectangular flake. The particles of IBU 45 present a slender column shape, while the images of IBU 3 are near-circular shape and the particle size is smaller than $\beta-C D$ and IBU 45. In the images of PMs both IBU and $\beta-C D$ crystals can be detected. Furthermore, in the IBU 45 PMs, the particles of IBU are smaller than pure IBU 45 , which is attributed to the grinding during the mixing process. On the contrary, the morphology of inclusion complexes has been considerably changed

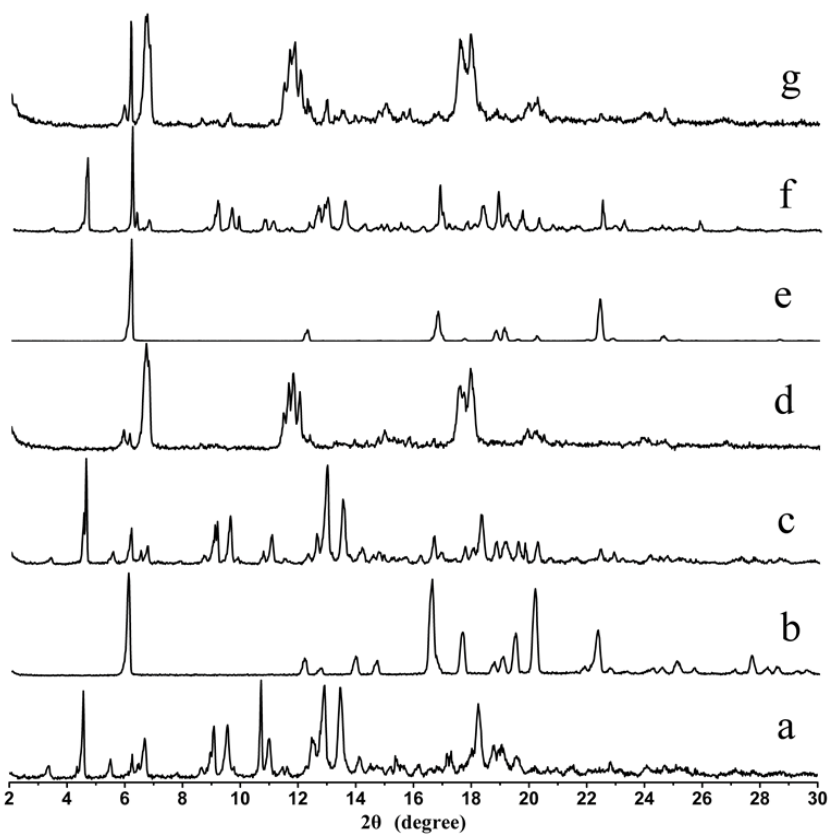

Fig. 6: XRPD patterns

a. IBU 3, b. IBU 45, c. $\beta$-cyclodextrin, d. physical mixture with IBU 3, e. physical mixture with IBU 45, f. inclusion complex with IBU 3 and g. inclusion complex with IBU 45 
and presents no apparent $\beta-\mathrm{CD}$ and IBU particles. This difference in the morphology of PMs and inclusion complexes particles may indicate the formation of a new entity. However, the morphology of inclusion complexes prepared with IBU 3 and IBU 45 shows no obvious difference (fig. 7).

Dissolution profiles for pure drugs, PMs, and inclusion complexes are presented in fig. 8 to demonstrate the influence of particle size reduction on the drug/cyclodextrin complex dissolution rate. In the dissolution study, the dissolution profiles of the inclusion complexes showed significant higher solubility and faster dissolution rate of IBU compared to the PMs and drug powder. Dissolution efficiency calculated at 30 and 120 min $\left(\mathrm{DE}_{30}\right.$ and $\left.\mathrm{DE}_{120}\right)$, were measured for all products studied (Table 1). Among the inclusion complexes tested, the inclusion complexes prepared with IBU 3 provided faster dissolution rate than IBU 45, which was attributed to the residual free drug in the IBU 3 inclusion complexes with smaller particle size. The same results were detected in IBU 3 physical mixture and IBU 3 free drug compared
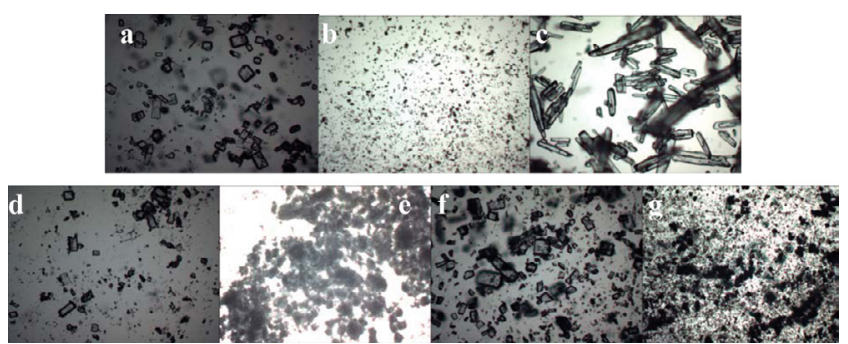

Fig. 7: Optical microscopy

a. IBU 3, b. IBU 45, c. $\beta$-cyclodextrin, d. physical mixture with IBU 3, e. physical mixture with IBU 45, f. inclusion complex with IBU 3 and g. inclusion complex with IBU 45

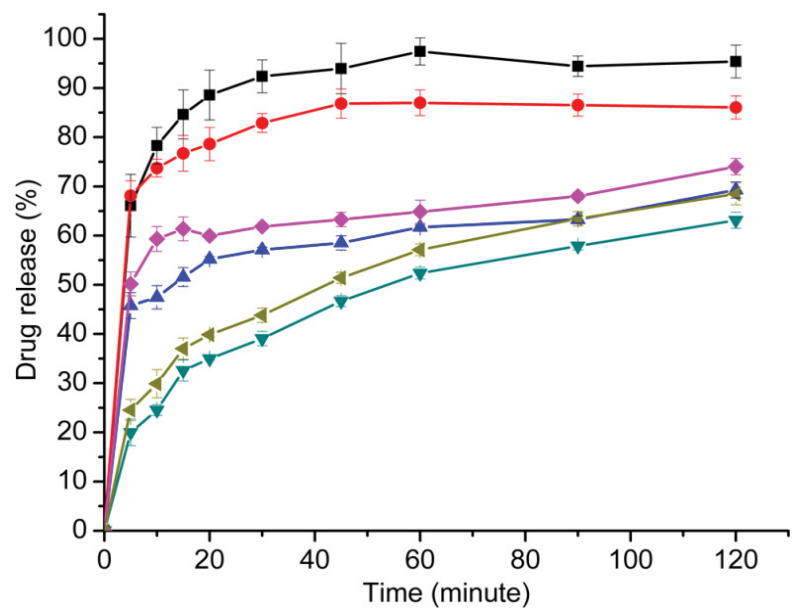

Fig. 8: Dissolution curves of inclusion complexes, physical mixtures and drug alone

The values are in mean $\pm S D, n=3$, - $\square$ - IBU 3 inclusion complex, - $\bullet$ - IBU 45 inclusion complex, - $\downarrow$ - IBU 3 physical mixture, - $\triangle$ IBU 45 physical mixture, - 4 - IBU 3, - $\nabla$ - IBU 45
TABLE 1: EFFECT OF B-CYCLODEXTRIN AND PARTICLE SIZE ON THE DISSOLUTION EFFICIENCY OF IBU

\begin{tabular}{|c|c|c|}
\hline Products & $\mathrm{DE}_{30}(\%)$ & $\mathrm{DE}_{120}(\%)$ \\
\hline \multicolumn{3}{|c|}{ Effect of B-cyclodextrin } \\
\hline IBU 3 (control) & $43.82 \pm 1.45$ & $68.49 \pm 2.24$ \\
\hline Inclusion complex with & $92.38 \pm 3.33^{* * *}$ & $95.38 \pm 3.32^{* * *}$ \\
\hline \multicolumn{3}{|l|}{ IBU 3} \\
\hline IBU 45 (control) & $39.07 \pm 1.45$ & $63.11 \pm 1.64$ \\
\hline Inclusion complex with & $82.88 \pm 1.92^{* * *}$ & $86.05 \pm 2.34^{* * *}$ \\
\hline \multicolumn{3}{|l|}{ IBU 45} \\
\hline \multicolumn{3}{|c|}{ Effect of particle size of IBU } \\
\hline Inclusion complex with & $82.88 \pm 1.92$ & $86.05 \pm 2.34$ \\
\hline \multicolumn{3}{|l|}{ IBU 45 (control) } \\
\hline Inclusion complex with & $92.38 \pm 3.33$ & $95.38 \pm 3.32$ \\
\hline IBU 3 & & \\
\hline
\end{tabular}

to IBU 45 physical mixture and IBU 45 free drug. Furthermore, the two PMs showed faster dissolution rate than corresponding free drug of IBU3 and IBU 45, which was attributed to the wettability of $\beta-C D$ and partly forming inclusion complex ${ }^{[32]}$ (fig. 8, Table 1).

In the present study, we first demonstrated the effect of drug particle size on complexation efficiency, physicochemical properties and dissolution of cyclodextrin inclusion complexes. Physicochemical characterization studies confirmed both IBU 3 and IBU 45 could form stable inclusion complexes with $\beta$-CD. IBU 3 with smaller particle size could improve the complexation efficiency comparing with IBU 45. Moreover, IBU 3 was more effective to form inclusion complex with $\beta$-CD because it could rapidly form inclusion complex in complexation kinetics study. In the dissolution study, the inclusion complexes prepared with IBU 3 presented the fastest dissolution rate in all binary systems and pure drugs. In conclusion, combining the techniques of drug particle size reduction with $\mathrm{CD}$ inclusion complex is a more effective way to improve the solubility and dissolution rate of poorly water-soluble drugs.

\section{Acknowledgments:}

The authors thank International Specialty Products Inc. for their generosity. This work is supported by National Natural Science Foundation of China (Grant No.81274034) and the Science and Technology Plan Projects of Xuzhou (KC14SH077).

\section{Conflict of interest:}

The authors declare no conflicts of interest. 


\section{Financial support and sponsorship:}

Nil.

\section{REFERENCES}

1. Kim JY, Kim S, Papp M, Park K, Pinal R. Hydrotropic solubilization of poorly water-soluble drugs. J Pharm Sci 2010;99:3953-65.

2. Lipinski CA, Lombardo F, Dominy BW, Feeney PJ. Experimental and computational approaches to estimate solubility and permeability in drug discovery and development. Adv Drug Deliv Rev 2001;46:3-26.

3. Karmarkar AB, Gonjari ID, Hosmani AH. Liquisolid technology for dissolution rate enhancement or sustained release. Expert Opin Drug Deliv 2010;7:1227-34.

4. Tran PHL, Tran TTD, Lee KH, Kim DJ, Lee BJ. Dissolutionmodulating mechanism of $\mathrm{pH}$ modifiers in solid dispersion containing weakly acidic or basic drugs with poor water solubility. Expert Opin Drug Deliv 2010;7:647-61.

5. He CX, He ZG, Gao JQ. Microemulsions as drug delivery systems to improve the solubility and the bioavailability of poorly water-soluble drugs. Expert Opin Drug Deliv 2010;7:445-60.

6. Fahr A, Liu X. Drug delivery strategies for poorly watersoluble drugs. Expert Opin Drug Deliv 2007;4:403-16.

7. Laza-Knoerr A, Gref R, Couvreur P. Cyclodextrins for drug delivery. J Drug Target 2010; 18:645-56.

8. Loftsson T, Jarho P, Másson M, Järvinen T. Cyclodextrins in drug delivery. Expert Opin Drug Deliv 2005;2:335-51.

9. Davis ME, Brewster ME. Cyclodextrin-based pharmaceutics: past, present and future. Nat Rev Drug Discov 2004;3:102335.

10. Loftsson T, Duchene D. Cyclodextrins and their pharmaceutical applications. Int J Pharm 2007;329:1-11.

11. Loftsson $\mathrm{T}$, Brewster ME. Cyclodextrins as functional excipients: methods to enhance complexation efficiency. J Pharm Sci 2012;101:3019-32.

12. Redenti E, Szente L, Szejtli J. Cyclodextrin complexes of salts of acidic drugs. Thermodynamic properties, structural features, and pharmaceutical applications. J Pharm Sci 2001;90:979-86.

13. Hussein K, Türk M, Wahl MA. Comparative evaluation of ibuprofen/ $\beta$-cyclodextrin complexes obtained by supercritical carbon dioxide and other conventional methods. Pharm Res 2007;24:585-92.

14. Lazzara G, Milioto S. Copolymer cyclodextrin Inclusion Complexes in Water and in the Solid State. A PhysicoChemical Study. J Phys Chem B 2008;112:11887-95.

15. Heidel J. Linear cyclodextrin-containing polymers and their use as delivery agents. Expert Opin Drug Deliv 2006;3:641-6.

16. Lee PYH, Sathigari S, Lin JYJ, Ravis WR, Chadha G, Parsons $\mathrm{DL}$, et al. Gefitinib-cyclodextrin inclusion complexes: physico-chemical characterization and dissolution studies. Drug Dev Ind Pharm 2009;35:1113-20.

17. Le $\mathrm{V}$, Leterme $\mathrm{P}$, Gayot $\mathrm{A}$, Flament M. Influence of granulation and compaction on the particle size of ibuprofen-development of a size analysis method. Int J Pharm 2006;321:72-7.
18. Yu LX, Amidon GL, Polli JE, Zhao H, Mehta MU, Conner DP, et al. Biopharmaceutics classification system: the scientific basis for biowaiver extensions. Pharm Res 2002;19:921-5.

19. Wikarsa S, Durand D, Delarbre JL, Baylac G, Bataille B. The improvement of Ibuprofen dissolution rate through microparticles spray drying processed in an aqueous system. Drug Dev Ind Pharm 2008;34:485-91.

20. Higuchi T, Connors KA. Phase-solubility techniques. Adv Anal Chem Instrum 1965;4:117-212.

21. Loftsson T, Hreinsdóttir D, Masson M. Evaluation of cyclodextrin solubilization of drugs. Int J Pharm 2005;302:1828.

22. Ghorab MK, Adeyeye MC. Elucidation of solution state complexation in wet-granulated oven-dried ibuprofen and $\beta$-cyclodextrin: FT-IR and ${ }^{1} \mathrm{H}-\mathrm{NMR}$ studies. Pharm Dev Technol 2001;6:315-24.

23. Salústio P, Feio G, Figueirinhas J, Pinto J, Cabral Marques H. The influence of the preparation methods on the inclusion of model drugs in a $\beta$-cyclodextrin cavity. Eur J Pharm Biopharm 2009;71:377-86.

24. Subramaniam P, Mohamad S, Alias Y. Synthesis and characterization of the inclusion complex of dicationic ionic liquid and $\beta$-cyclodextrin. Int J Mol Sci 2010;11:3675-85.

25. Sravani B, Deveswaran R, Bharath S, Basavaraj B, Madhavan V. Studies on Vigna mungo mucilage as a pharmaceutical excipients. J Chem Pharm Res 2011;3:118-25.

26. Dandawate PR, Vyas A, Ahmad A, Banerjee S, Deshpande $\mathrm{J}$, Swamy KV, et al. Inclusion complex of novel curcumin analogue CDF and $\beta$-cyclodextrin (1:2) and its enhanced in vivo anticancer activity against pancreatic cancer. Pharm Res 2012;29:1775-86.

27. Battu SK, Repka MA, Maddineni S, Chittiboyina AG, Avery MA, Majumdar S. Physicochemical characterization of berberine chloride: a perspective in the development of a solution dosage form for oral delivery. AAPS PharmSciTech 2010;11:1466-75.

28. Zhang J, Huang Y, Liu D, Gao Y, Qian S. Preparation of apigenin nanocrystals using supercritical antisolvent process for dissolution and bioavailability enhancement. Eur J Pharm Sci 2013;48:740-7.

29. Sami F, Philip B, Pathak K. Effect of auxiliary substances on complexation efficiency and intrinsic dissolution rate of gemfibrozil- $\beta-C D$ complexes. AAPS PharmSciTech 2010;11:27-35.

30. Aigner Z, Berkesi O, Farkas G, Szabó-Révész P. DSC. X-ray and FTIR studies of a gemfibrozil/dimethyl- $\beta$-cyclodextrin inclusion complex produced by co-grinding. J Pharm Biomed Anal 2012;57:62-7.

31. Doile MM, Fortunato KA, Schmücker IC, Schucko SK, Silva MAS, Rodrigues PO. Physicochemical Properties and Dissolution Studies of Dexamethasone Acetate- $\beta$ Cyclodextrin Inclusion Complexes Produced by Different Methods. AAPS PharmSciTech 2008;9:314-21.

32. Alsarra IA, Alanazi FK, Ahmed SM, Bosela AA, Alhamed SS, Mowafy HA, et al. Comparative study of itraconazolecyclodextrin inclusion complex and its commercial product. Arch Pharm Res 2010;33:1009-17. 